\title{
Malignant Ovarian Sex Cord Tumor with Annular Tubules in a Patient with Peutz-Jeghers Syndrome: A Case Report
}

\author{
Subodh M. Lele, M.D., Ravindranauth N. Sawh, M.B.B.S., D.M., Paul Zaharopoulos, M.D., \\ Adekunle Adesokan, M.D., Michael Smith, M.D., Jessica M. Linhart, M.D., Concepcion D. Arrastia, M.D., \\ Hannah R. Krigman, M.D. \\ Department of Pathology (SML, RNS, PZ, MS, HRK) and Department of Obstetrics and Gynecology, \\ Division of Gynecologic Oncology (JML, CDA), University of Texas Medical Branch, Galveston, Texas; \\ Department of Pathology, St. Barnabas Medical Center (AA), Livingston, New Jersey; and Department of \\ Pathology, Missouri Baptist Hospital, St. Louis, Missouri (HRK)
}

The majority of ovarian sex cord tumors with annular tubules (SCTAT) are benign neoplasms that arise sporadically. In patients who have Peutz-Jeghers syndrome (PJS), ovarian SCTAT is often an incidental finding. Malignant behavior in SCTAT has heretofore been reported only in sporadic cases. We report a case of bilateral, malignant SCTAT developing in a 47-year-old woman who had PJS, originally diagnosed as adenocarcinoma on cervicovaginal cytology. Cervicovaginal and peritoneal fluid cytologic preparations were characterized by pseudopapillary clusters and three-dimensional tubes of tumor cells with scanty cytoplasm and high nuclear: cytoplasmic ratio. Examination of surgical resection specimens revealed bilateral, solid ovarian tumors composed of simple and complex annular tubules with hyaline cores, typical of SCTAT. Tumor emboli were present within salpingeal lymphovascular spaces and in both right and left pelvic lymph nodes. Flow cytometry of tumor cells demonstrated a diploid phenotype. This case represents the first documented example of bilateral, malignant SCTAT arising in a patient who had PJS, presenting with an atypical cervicovaginal smear.

KEY WORDS: Cytology, Ovarian neoplasms, PeutzJeghers syndrome, Ploidy, Sex cord tumor with annular tubules.

Mod Pathol 2000;13(4):466-470

Copyright $(\odot 2000$ by The United States and Canadian Academy of Pathology, Inc.

VOL. 13, NO. 4, P. 466, 2000 Printed in the U.S.A.

Date of acceptance: October 26, 1999.

Presented in part as a Resident's Poster at the 77th Annual Meeting of the Texas Society of Pathologists, Houston, TX, February 6-7, 1998.

Address reprint requests to: Hannah R. Krigman, M.D., Department of Pathology, Missouri Baptist Hospital, 3015 N. Ballas Road, St. Louis, MO 63131; e-mail: hrkrigma@utmb.edu.
Ovarian sex cord tumors with annular tubules (SCTAT) were first described by Scully in 1970 (1). Three of the 10 index patients also had PeutzJeghers syndrome (PJS). Both sporadic and PJSassociated SCTAT have since been reported in patients ranging in age from 4 to $76 \mathrm{y}$, with most being diagnosed in the third or fourth decade of life (2). These tumors may be feminizing, inducing isosexual precocity, menstrual irregularities, and postmenopausal bleeding in young girls, women of reproductive age, and postmenopausal women, respectively $(2,3)$. When occurring in association with PJS, they typically are bilateral, multifocal, small $(<3 \mathrm{~cm})$, and benign (2). This report describes bilateral, malignant, ovarian SCTAT arising in a $47-$ year-old woman who had documented PJS.

\section{MATERIALS AND METHODS}

\section{Case Report}

A 47-year-old woman who had previously diagnosed PJS presented to a University of Texas Medical Branch clinic in November 1997 for evaluation of a 5-mo history of irregular vaginal bleeding. Three months earlier, a cervicovaginal smear had been reported as adenocarcinoma with papillary features. However, two subsequent cervical biopsies, including a loop electrocautery excision procedure, had demonstrated only inflammatory and reactive changes. Similarly, there was no evidence of neoplasia in two consecutive endometrial biopsies that demonstrated only shedding and proliferative phase endometrium, respectively. The medical history was remarkable for a small bowel segmental resection at the age of $14 \mathrm{y}$ for bleeding "adenomatous" polyps. However, review of the original histologic slides revealed that the polyps were, in fact, hamartomatous in nature, typical of 
PJS polyps. The clinical diagnosis of PJS was confirmed by the fact that three of her four teenage children exhibited prominent perioral hyperpigmentation, and all three had previously undergone abdominal surgery for complications related to the presence of small intestinal hamartomatous polyps.

Initial physical examination, inclusive of a bimanual pelvic examination, was unremarkable. However, pelvic ultrasonography revealed a solid, left ovarian mass with minimal free ascites. Four weeks later, an immobile mass was palpated in the left adnexal region. Exploratory laparotomy revealed $75 \mathrm{~mL}$ of ascites; an 8.5 -cm left ovarian mass; a 3.5-cm right ovary; and prominent, bilateral pelvic lymphadenopathy. After frozen section examination and diagnosis, the patient was subjected to total abdominal hysterectomy, bilateral salpingooophorectomy, and staging lymph node dissection. There was no gross residual disease after resection.

After the surgery, the patient was scheduled to receive four cycles of bleomycin $\left(10 \mathrm{U} / \mathrm{m}^{2}\right)$, etoposide $\left(100 \mathrm{mg} / \mathrm{m}^{2}\right)$, and cis-platinum $\left(20 \mathrm{mg} / \mathrm{m}^{2}\right)$. However, after the first cycle, she developed severe (Grade 4) bone marrow toxicity and the etoposide dose was reduced to $50 \mathrm{mg} / \mathrm{m}^{2}$ for the remaining three cycles. At last follow-up, 28 mo after resection, she remained free of disease.

\section{Cytologic Findings}

The cervicovaginal smear was satisfactory for evaluation but limited by drying artifact and obscuring blood. Although the sample contained fresh hemorrhage, there was no background tumor diathesis. Rare papilliform and elongated ramifying structures, consisting of tightly packed cells having a high nuclear:cytoplasmic $(\mathrm{N}: \mathrm{C})$ ratio, were identified (Fig. 1). Some of these structures seemed to have a central fibrovascular core.

Filter and cytospin preparations of the peritoneal washings obtained at laparotomy were stained by the Papanicolaou method. Tumor cells were arranged in three-dimensional balls and cords, lumenless tubules, and irregular clusters. Polarization of nuclei away from the center of the cell clusters was seen. Cell borders were indistinct, and individual cells had a high $\mathrm{N}: \mathrm{C}$ ratio with a scant to moderate amount of lightly cyanophilic, finely vacuolated cytoplasm. Nuclear diameter was approximately one half that of adjacent mesothelial cell nuclei, and nuclear contours were smooth or minimally irregular. Nuclear chromatin was finely granular and hyperchromatic, whereas nucleoli were small but distinct. Intraoperative touch preparations of the left ovarian tumor were stained with hematoxylin and eosin (immediate fixation), with Diff-Quik (air-dried samples; Dade Behring AG, Diidingen, Switzerland), and by the Papanicolaou method (alcohol fixation). These showed central

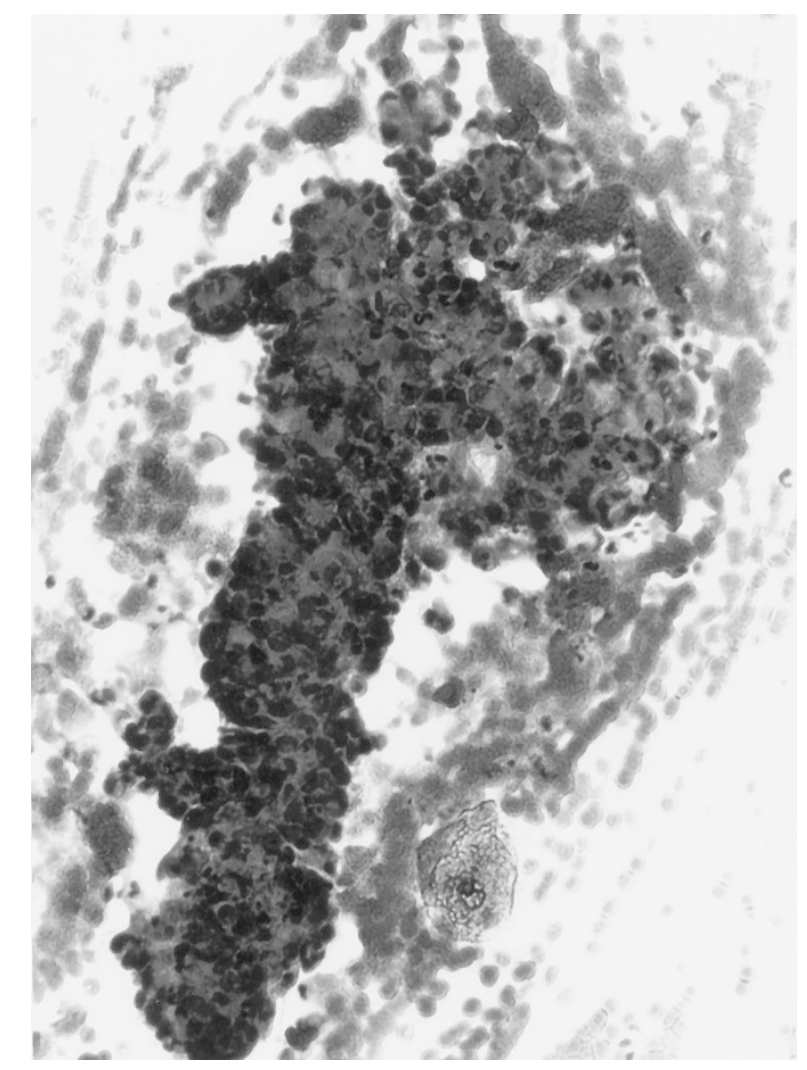

FIGURE 1. Cervicovaginal smear. Papilliform structure composed of tightly packed cells with high nuclear:cytoplasmic ratio (Papanicolaou stain; original magnification, $400 \times$ ).

cores of acellular hyaline material surrounded by cells having cytologic features similar to those observed in the peritoneal washings (Fig. 2).

\section{Gross and Histologic Findings}

The left ovary measured $8.5 \times 6.0 \times 6.0 \mathrm{~cm}$ and weighed $120 \mathrm{~g}$. The external surface was smooth, whereas the cut surface was firm, solid, and bright yellow. Occasional foci of cystic degeneration, ranging in diameter from 0.2 to $3 \mathrm{~cm}$, were present (Fig. $3)$. Residual normal ovarian tissue was not identified. The right ovary measured $3.5 \times 3.3 \times 2.6 \mathrm{~cm}$ and was similarly replaced by solid, yellow tumor. The uterus, cervix, and fallopian tubes had a combined weight of $160 \mathrm{~g}$ and were remarkable only for the presence of a $0.4-\mathrm{cm}$ endometrial polyp.

Histologically, both ovaries were completely replaced by tumor having the typical cytoarchitectural features of SCTAT. Simple and complex tubules encircled hyaline cores (Fig. 4). The cytoplasm of the cells lining the tubules was pale, and the nuclei were arranged in an antipodal fashion around both the central core and the periphery of individual tubules. In addition, the right ovarian tumor contained a few foci of more elongated tubules, a microscopic focus of cells arranged in a diffuse pattern, and rare foci of microcalcification. Microscopic surface deposits of tu- 


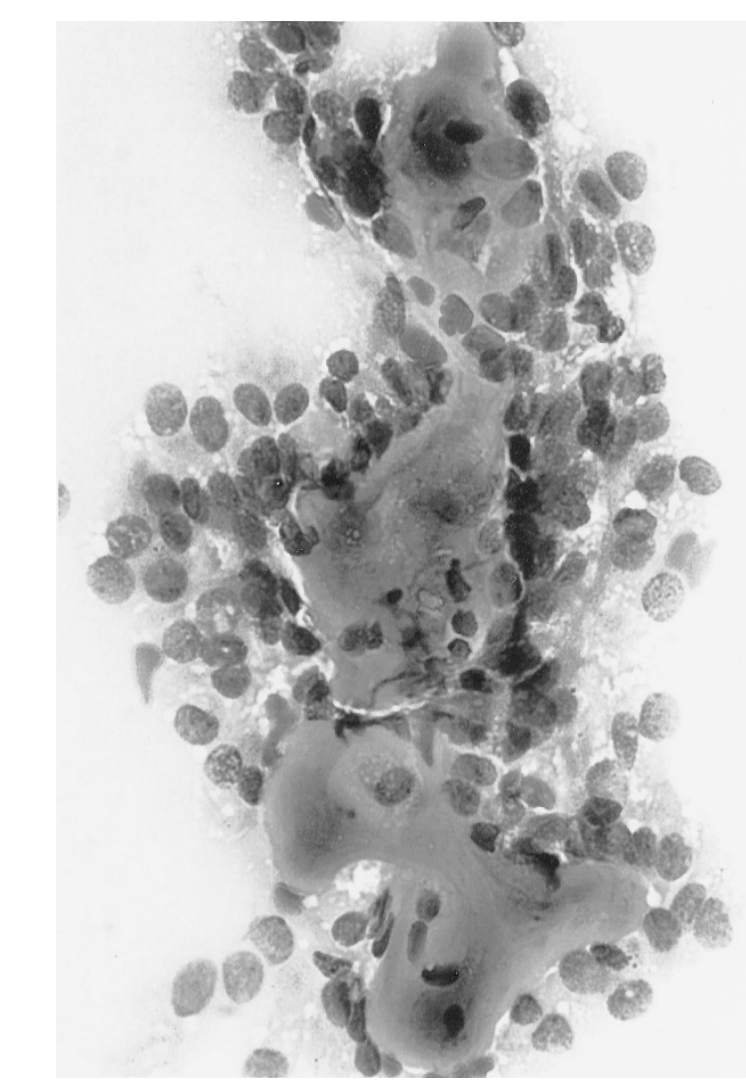

FIGURE 2. Left ovarian tumor, touch imprint. Tumor cells with high nuclear:cytoplasmic ratio, vacuolated cytoplasm, and fine nuclear chromatin surround acellular hyaline cores (Diff-Quik stain; origina magnification, $400 \times)$.

mor, associated with delicate fibrous adhesions, were also noted. Mitotic activity in both tumors was minimal. Tumor emboli permeated lymphovascular spaces of the left fallopian tube. Subcapsular deposits of tumor were identified in 1 of 10 right and 2 of 7 left pelvic lymph nodes, respectively (Fig. 5). Flow cytometric studies revealed a diploid tumor cell population, with an S-phase fraction of $7.6 \%$. The American Joint Committee on Cancer pathologic stage for the tumor was T2c Nl MX (Stage IIIC) (4).

The uterine cervix was free of both squamous and glandular neoplasia. The endometrium had a disordered proliferative pattern and a benign endometrial polyp.

\section{DISCUSSION}

This article describes a hitherto undocumented manifestation of an uncommon tumor, namely, malignant behavior of PJS-associated SCTAT. Malignant behavior was evidenced by tumor involvement of salpingeal lymphovascular spaces, pelvic lymph nodes, and peritoneal washings. We are unaware of any previous reports of clinically malignant PJS-associated SCTAT and could find no such case in a computer-assisted MEDLINE literature search extending from 1962 to the present. In the

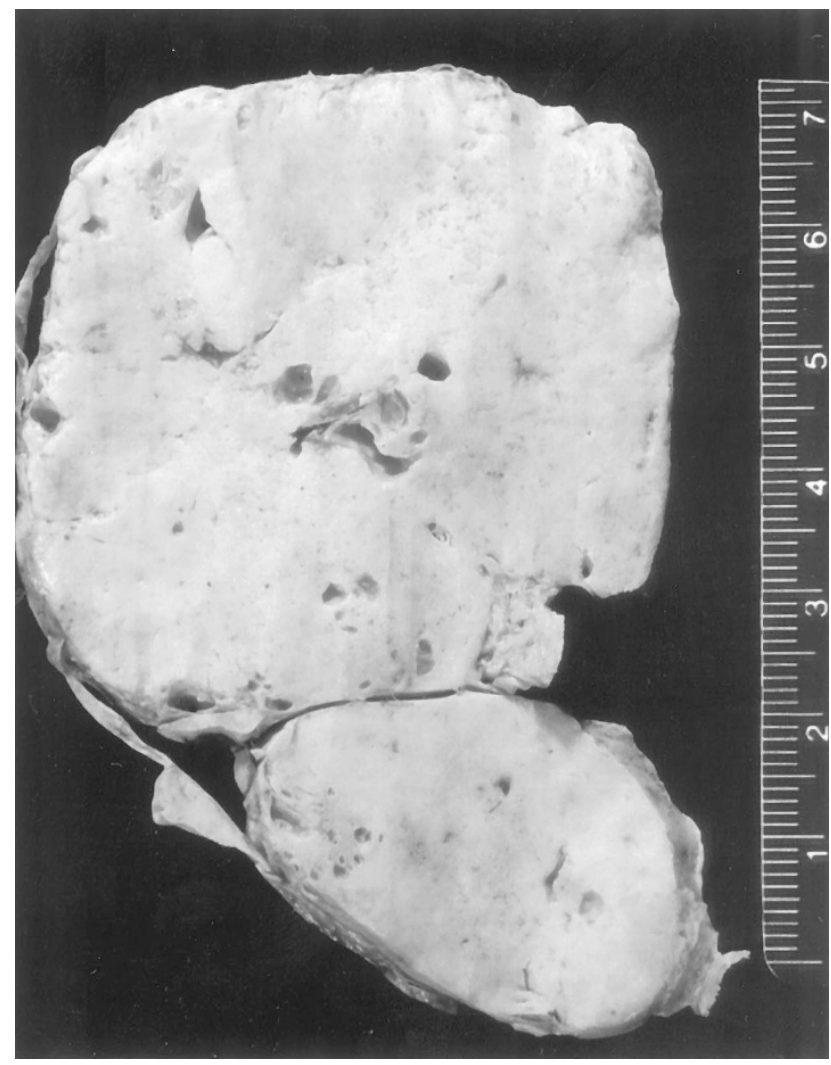

FIGURE 3. Left ovarian tumor, cut surface. The tumor is bilobate and largely solid, with scattered foci of cystic degeneration (Gross).

largest series of SCTAT to date, none of the 27 patients with both PJS and SCTAT exhibited tumor recurrence or metastasis in reported follow-up intervals ranging from 6 mo to $11 \mathrm{y} \mathrm{(2).} \mathrm{To} \mathrm{date,} \mathrm{all}$ examples of malignant SCTAT reported in the literature have occurred in patients who did not have PJS (2, 5-11).

The gross morphologic findings of the ovarian tumors in this case differed appreciably from those generally seen in association with PJS. SCTAT associated with PJS are often multifocal and small $(<3$ $\mathrm{cm})(1,2)$. Both tumors in this case were unusually large for PJS-associated SCTAT, measuring 8.5 and $3.5 \mathrm{~cm}$ on the left and right sides, respectively. Although the 13 previously reported cases of malignant SCTAT also were relatively large, with diameters ranging from 11 to $22 \mathrm{~cm}$, all proved to be unilateral $(2,5-11)$. In this regard, the finding in our case of large bilateral tumors associated with bilateral pelvic lymph node metastasis is also unique. Adherence to pelvic structures, documented in one previous report of malignant SCTAT (6), was not present in our case despite the microscopic finding of rare surface deposits of tumor associated with delicate fibrous adhesions. Calcification, a frequently reported feature of SCTAT associated with PJS, was present only as rare microscopic foci in the smaller right ovarian tumor. 

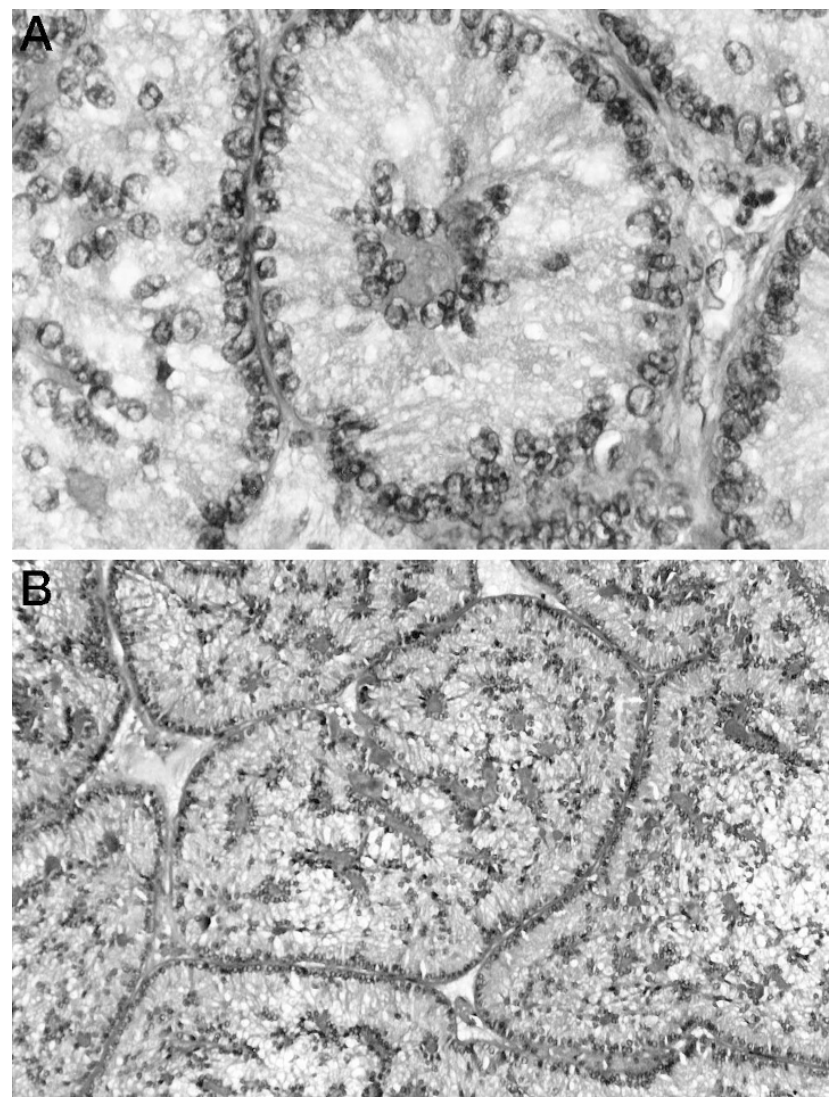

FIGURE 4. Left ovarian tumor, histology. Both simple (A) and complex (B) annular tubules, composed of cells with an antipodal arrangement of nuclei, encircle central hyaline material (hematoxylin and eosin stain; original magnification, $400 \times[\mathrm{A}]$ and $200 \times[\mathrm{B}])$.

The histologic findings in both ovarian tumors of simple and complex annular tubules encircling central hyaline masses were typical of SCTAT. Other features noted in the right-sided tumor, such as foci of more elongated tubules and a diffuse pattern of arrangement of tumor cells, are also well documented. However, previous reports of both benign and malignant SCTAT, including both sporadic and PJS-associated tumors, have described additional histologic patterns such as sertoliform tubules, endometrioid areas, and foci of granulosa cell-like differentiation $(1,6,7,12-14)$. On the basis of such findings, some authors have suggested that SCTAT represent variants of either Sertoli cell or granulosa cell tumors, whereas others regard SCTAT as distinctive neoplasms with features intermediate between those of Sertoli cell and granulosa cell tumors $(1,2,6,7)$. Neither solid and hollow tubules typical of Sertoli cell tumor nor foci histologically resembling granulosa cell tumor were observed in either tumor in this case.

The malignant potential of SCTAT cannot be reliably predicted by microscopic examination of the primary tumor. Mitotic counts in the 13 reported malignant cases ranged from rare to 7 to 10 mitoses per 10 high power fields $(2,5-9,11)$. Stromal and

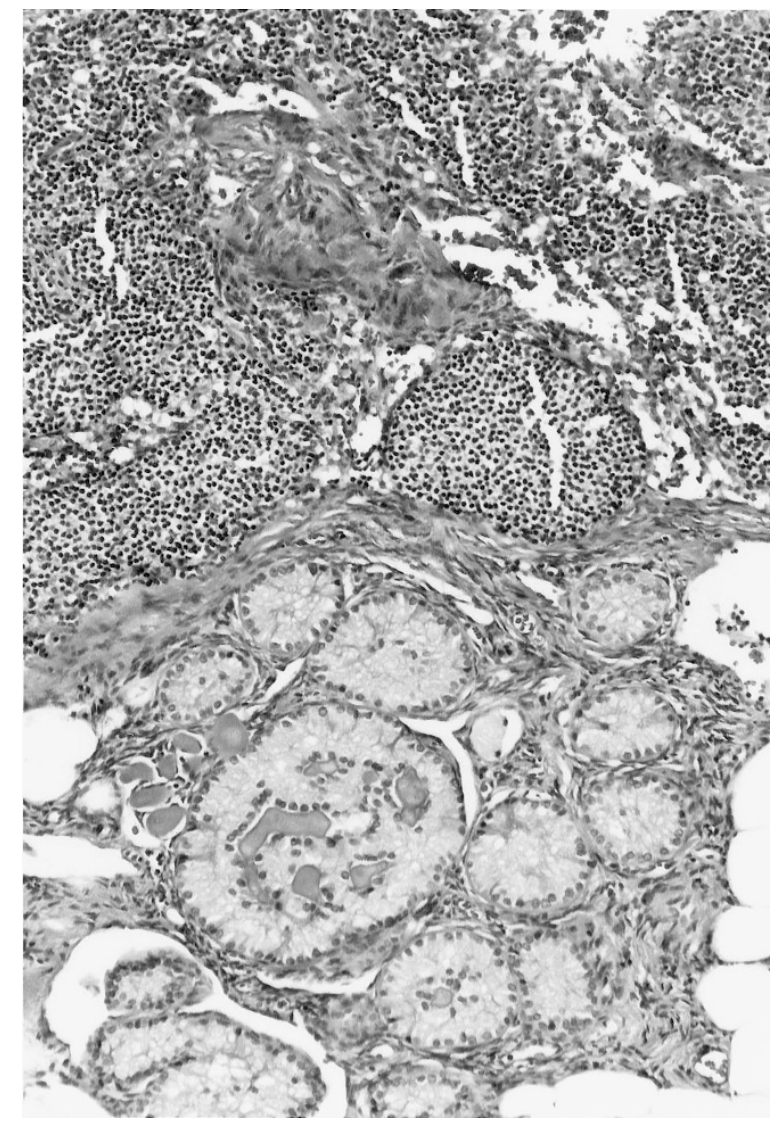

FIGURE 5. Left pelvic lymph node with metastatic tumor deposit (hematoxylin and eosin stain; original magnification, 200×).

vascular space invasion by individual tumor cells and tumor cell clusters has been reported in two cases of recurrent SCTAT, one of which also had infiltrated the capsule (6). The time of first recurrence in cases of malignant SCTAT has ranged from 3 mo to $20 \mathrm{y}$, and six patients reportedly have died of disease (2, 5-11). Malignant SCTAT seems to spread mainly via the lymphatics with typical sites of tumor metastasis being the pelvic, para-aortic, and supraclavicular lymph nodes. Other sites of tumor recurrence and metastasis include the retroperitoneum, parietal and visceral peritoneum, liver, kidney, and lung (2, 5-11). Unique to our case were the presence of tumor emboli in lymphovascular spaces of the left salpingeal mucosa and the identification of tumor cells in a cervicovaginal smear.

Recognition of tumor cells in the peritoneal washings was based, in part, on comparison with intraoperative touch preparations, because the cytologic features of this rare tumor have not been well described. A single report described the appearance of SCTAT on fine needle aspiration as being indistinguishable from that of a granulosa cell tumor (15). In our case, the finding of clusters of cells disposed about hyaline cores, which were amphophilic with Diff-Quik staining and glassy green on Papanicolaou staining, was not dissimilar 
to that described for the Call-Exner bodies of granulosa cell tumors. However, nuclear grooves, a hallmark of adult-type granulosa cell tumors, were not present.

The index material for this case report was a cervicovaginal cytologic sample containing rare papilliform fragments. The latter, consisting of cells of high $\mathrm{N}: \mathrm{C}$ ratio arranged around seeming fibrovascular cores, suggested the diagnosis of papillary carcinoma. Only in retrospect were these seeming fibrovascular cores interpreted as representing the hyaline cores of basement membrane-like material typical of SCTAT. Certainly, detection of ovarian neoplasms via cervicovaginal cytology is uncommon. In large series, fewer than $0.01 \%$ of cervicovaginal cytologic samples contain atypical glandular lesions or psammoma bodies ultimately proved to be of ovarian origin $(16,17)$. However, up to $3.6 \%$ of ovarian neoplasms are detectable as glandular clusters on cervicovaginal cytology (18), with the majority of these being serous tumors (19). Ascites, present in the current case, may facilitate transsalpingeal spread (20). Our experience in this case is supportive of the diagnostic utility of pelvic ultrasonography in the workup of atypical glandular cells in a cervicovaginal smear.

In summary, we report a case of PJS-associated, bilateral, malignant SCTAT, with trans-salpingeal lymphatic spread, presenting as an abnormality on a cervicovaginal smear. Counseling of female patients who have PJS should take into account the possibility of malignant behavior of ovarian SCTAT.

\section{REFERENCES}

1. Scully RE. Sex cord tumor with annular tubules: a distinctive ovarian tumor of the Peutz-Jeghers syndrome. Cancer 1970; 25:1107-21.

2. Young RH, Welch WR, Dickersin GR, Scully RE. Ovarian sex cord tumor with annular tubules: review of 74 cases including 27 with Peutz-Jeghers syndrome and four with adenoma malignum of the cervix. Cancer 1982;50:1384-402.
3. Solh HM, Azoury RS, Najjar SS. Peutz-Jeghers syndrome associated with precocious puberty. J Pediatr 1983;103:593-5.

4. American Joint Committee on Cancer. AJCC cancer staging manual. 5th ed. New York: Lippincott-Raven; 1997. pp. 201-6.

5. Gloor E. Ovarian sex cord tumor with annular tubules. Virchows Arch A 1979;384:185-93.

6. Tavassoli FA, Norris HJ. Sertoli tumors of the ovary. Cancer 1980;46:2281-97.

7. Hart WR, Kumar N, Crissman JD. Ovarian neoplasms resembling sex cord tumors with annular tubules. Cancer 1980;45: 2352-63.

8. Matamala MF, Nogales FF, Lardelli P, Navarro N. Metastatic granuloma cell tumor with pattern of sex cord tumor with annular tubules. Int J Gynecol Pathol 1987;6:185-93.

9. Ahn GH, Chi JG, Lee SK. Ovarian sex cord tumor with annular tubules. Cancer 1986;57:1066-73.

10. Shen K, Wu PC, Lang JH, Huang RL, Tang MT, Lian LJ. Ovarian sex cord tumor with annular tubules: a report of six cases. Gynecol Oncol 1993;48:180-4.

11. Gustafson ML, Lee MM, Scully RE, Moncure AC, Hirakawa T, Goodman A, et al. Mullerian inhibiting substance as a marker for ovarian sex cord tumor. N Engl J Med 1992;326: 466-71.

12. Kalifat R, de Brux J. Ovarian sex cord tumor with annular tubules: an ultrastructural study. Int J Gynecol Pathol 1987; 6:380-8.

13. Takeshima Y, Inai K. Ovarian sex cord tumor with annular tubules: a case report and review of the literature in Japanese. Hiroshima J Med Sci 1992;41:37-42.

14. Czernobilsky B, Gaedcke G, Dallenbach-Hellweg G. Endometrioid differentiation in ovarian sex cord tumor with annular tubules accompanied by gestagenic effect. Cancer 985; 55:738-44.

15. Yazdi HM. Fine needle aspiration cytology of ovarian sex cord tumor with annular tubules. Acta Cytol 1987;31:340-4.

16. Ken SB. Prevalence of psammoma bodies in Papanicolaoustained cervicovaginal smears. Acta Cytol 1991;35:81-8.

17. Lyon DS, Kaminski PF, Wheelock JB. Significance of a positive Papanicolaou smear in a well screened population. South Med J 1989;82:190-2.

18. Pairwuti S. Results of Pap smear examinations in women with abnormal ovaries. J Med Assoc Thai 1991;74:248-52.

19. Kanbour A, Doshi N. Psammoma bodies and detached ciliary tufts in a cervicovaginal smear associated with benign ovarian cystadenofibroma. Acta Cytol 1980;24:549-52.

20. Takashina T, Ono M, Kanda Y, Sagae S, Hayakawa O, Ito E. Cervicovaginal and endometrial cytology in ovarian cancer. Acta Cytol 1988;32:159-62. 